\title{
Calibration of ASM1 for Carbon and Nitrogen Removals of Riqqa Activated Sludge System, Kuwait
}

\author{
Abdallah Abusam
}

\begin{abstract}
Riqqa plant, the second largest wastewater treatment plant in Kuwait, has lately shown signs of working under unstable conditions. The Kuwait Institute for Scientific Research has conducted a study to evaluate the plant performance and to pin-point the probable causes of the problem. To achieve these objectives, the Riqqa activated sludge system was modelled using activated sludge model No. 1 (ASM1) in SIMBA simulation package. It was the first time to use ASM1 to model a full-scale activated sludge system in Kuwait. This paper presents the calibration of ASM1 to carbon and nitrogen removals of the Riqqa activated sludge system, using long-term routinely measured wastewater quality parameters. Repirometery analysis was used to help in chemical oxygen demand (COD) fractionation and for providing initial guess values for the calibrated parameters. Validation results showed reasonable agreement between the measured and simulated $\mathrm{COD}, \mathrm{NH}_{4}-\mathrm{N}$ and $\mathrm{NO}_{3}-\mathrm{N}$ over long-term dynamic simulation. The developed model was then used to evaluate and diagnose the system performance. The values of ASM1 parameters obtained will be useful in modelling other activated sludge systems in the country.
\end{abstract}

Index Terms-Activated sludge, performance simulation, modeling, calibration.

\section{INTRODUCTION}

Activated sludge process is the biological wastewater treatment method applied worldwide [1]. A dynamic model is usually required for simulating the performance of wastewater treatment processes. The widely used models for simulating activated sludge processes are the so-called activated sludge models (ASMs) developed by the International Water Association (IWA). ASM1 describes the removal processes of carbon and nitrogen from wastewater [2].

It is widely considered the state of the-art-model for activated sludge systems. Many scientific and practical projects conducted in developed countries refer to ASM1 [1]. In contrast, the use of ASM1 in developing countries is very limited [3].

Riqqa plant is the second largest plant in Kuwait. This plant has lately shown signs of working under unstable conditions [4], [5]. The Kuwait Institute for Scientific Research (KISR) has conducted a study to evaluate the performance of the Riqqa activated sludge system, identify the limiting operational factors and predict its future performance. The system was modeled using ASM1. It was

Manuscript received April 29, 2014; revised August 21, 2014. This work was support by the Kuwait Foundation for the Advancement of Sciences.

A. Abusam is with Kuwait Institute for Scientific Research, P. O. Box 24885, Safat 13109, Kuwait (e-mail: aabusam@kisr.edu.kw). the first time to use ASM1 to model a full-scale activated sludge system in Kuwait. This paper presents the calibration of ASM1 for carbon and nitrogen removals of Riqqa Activated Sludge System.

\section{PLANT DESCRIPTION}

Riqqa plant is the second largest wastewater plant in Kuwait. It is located west of Al-Zahr residential area of Kuwait. Its present design capacity is $180,000 \mathrm{~m}^{3} / \mathrm{d}$, and it mainly treats domestic wastewater of a medium strength. Its activated sludge system consists of 12 aeration tanks (total volume $=123379 \mathrm{~m}^{3}$ ) and 10 secondary clarifiers (total volume $=34020 \mathrm{~m}^{3}$ ). Riqqa plant treats up to tertiary level, using sand filtration and chlorination.

\section{MATERIAL AND METHODS}

\section{A. Model Development}

In SIMBA simulation platform, the system was modeled as an aeration tank and settling tank. ASM1 was used to model the biochemical processes taking place in the aeration tank. As recommended by the United States Environmental Protection Agency (US-EPA) [6], the equation proposed by Davis [7] was used to find out that 18 continuous stirred-tank reactor (CSTR) can reproduce the hydraulics of the aeration tanks. The secondary clarifier was modeled using the model developed by Takacs et al. [8].

\section{B. Sampling and Analysis Program}

Since the main objective of the study conducted by KISR was the assessment of the system performance, it was decided that long-term wastewater quality parameters routinely measured twice a week will be used. In addition, a four hours intensive sampling and analysis campaign, repeated on three different days, was conducted. Samples were collected from four locations along the activated sludge system: influent, aeration tank, clarifier underflow, and secondary effluent. Wastewater analysis was conducted according to the American Public Health Association's standard methods for the examination of water and wastewater [9]. Water temperature, $\mathrm{pH}$ and electrical conductivity were measured on-site using Hatch portable kits. Parameters determined at KISR laboratories were total chemical oxygen demand $\left(C O D_{\text {tot }}\right)$, soluble chemical oxygen demand $\left(C O D_{s o l}\right)$, five-days biological oxygen demand $\left(\mathrm{BOD}_{5}\right)$, total solids (TS), total suspended solids (TSS), total dissolved solids (TDS), volatile suspended solids (VSS), total phosphorus (TP), total Kajeldah nitrogen (TKN), organic nitrogen $(\mathrm{Org}-\mathrm{N})$, ammonia $\left(\mathrm{NH}_{4}\right)$, nitrite $\left(\mathrm{NO}_{2}\right)$, and nitrate $\left(\mathrm{NO}_{3}\right)$. 


\section{COD and TN Fractionation Methods}

In addition to the methods reported in literature, respirometry analysis was also carried out using BM-T Surcis respirometer to help determine the COD fractions and find values of the following ASM1 parameters: readily soluble organic $\left(S_{S}\right)$, slowly soluble organic $\left(X_{S}\right)$, decay rate of heterotrophic bacteria $\left(b_{H}\right)$, decay coefficient $\left(K_{d}\right)$, half-saturation coefficient for heterotrophic biomass $\left(K_{S}\right)$, and yield for heterotrophic biomass $\left(Y_{H}\right)$. From the respirometry analysis, average values of these parameters were found to be $95,61.3,0.66,0.66,0.03$, and 0.09 respectively. $\mathrm{Si}$ was assumed to be equal to $C O D_{\text {sol }}$ concentration in the effluent [2]. Further, the heterotrophic biomass $\left(X_{B H}\right)$ and autotrophic biomass $\left(X_{B A}\right)$ were assumed to be initially equal to $5 \% C O D_{\text {tot }}$ and $0.1 \% C O D_{\text {tot }}$, respectively. Furthermore, the inert component of $\operatorname{COD}\left(\mathrm{X}_{\mathrm{P}}\right)$ was assumed to be equal to zero. However, Xi was assumed to be a calibration parameter [10], initially equaling $50 \%$ of $C O D_{\text {tot }}$. Note that other ASM1 parameters were assigned SIMBA default values. Also, total nitrogen was fractionated as suggested by SIMBA.

\section{Model Calibration and Validation}

Steady-state calibrations were conducted mainly to calibrate the model to TSS values in the aeration tank and in the underflow of the clarifier. From steady-state simulations, the values of $b_{H}, b_{A}$ and $\mathrm{X}_{\mathrm{I}}$ were estimated.

Dynamic calibrations were conducted to calibrate the model to $C O D_{\text {tot }}, \mathrm{NO}_{3}$ and $\mathrm{NH}_{4}$ concentrations of the secondary effluent. The data used in the dynamic calibration were measurements taken twice a week during the period from March 2009 to September 2009. All model calibration trails were carried out manually where only one parameter was fine-tuned at a time. The following ASM1 sensitive parameters were calibrated: $Y_{H}, b_{H} K_{O, H}, b_{A}, K_{S}$ and $\eta_{g}$ [11], while other parameters were assigned SIMBA default values. Note that except $r_{p}$, all parameters of the clarifier were kept at SIMBA default values. According to Abusam and Keesman [12], $r_{p}$ is the most sensitive parameter of the secondary clarifier. Takacs et al. [8] recommend finding the value of $r_{p}$ by simulation.

The calibrated model was then validated using a different set of data obtained from October 2009 to March 2010. Also, for model validation, $C O D_{t o t}$ data were fractionated in the same way it was fractionated to calibrate model. However, the values of model parameters were not changed from that obtained by calibration.

\section{RESUlTS AND DisCUSSION}

Results obtained from steady-state calibrations have shown that $X_{I}$ is equal to $45 \%$ of $C O D_{\text {tot }}$, while $b_{H}$ and $b_{A}$ are equal to $0.10 \mathrm{~d}^{-1}$ and $0.05 \mathrm{~d}^{-1}$, respectively. These values compare well with the values reported in literature [13], [10]. On the other hand, dynamic calibration trials have resulted in the clarifier calibrated parameter, $r_{p}$ equaling to $6.86 \mathrm{~m}^{3} / \mathrm{g}$, while the ASM1 calibrated parameters $Y_{H}, K_{O H}, b_{H}, b_{A}, K_{S}$ and $\eta_{g}$ are equal to $0.67,0.5,0.1,0.05,30$, and 0.8 , respectively. These values are also within the ranges reported in literature for domestic wastewater [13], [14].
Fig. 1, Fig. 2 and Fig. 3 present the predictions of the calibrated model versus the measurements of $C O D_{t o t}, \mathrm{NO}_{3}$, and $\mathrm{NH}_{4}$, respectively. Fig. 1 shows that the model can predict most of the time the trends and dynamics of $C O D_{t o t}$ of the secondary effluent. The only significant mismatch between model predictions and actual measurements was shown to take place between days 70 to 110 . Similar results are also shown for the concentration of $\mathrm{NO}_{3}$ in Fig. 2. Fig. 3, however, shows that the model predicted accurately the measurements of $\mathrm{NH}_{4}$ (Fig. 3) until day 80, after which $\mathrm{NH}_{4}$ measurements were significantly higher than model predictions. High concentrations of $\mathrm{NH}_{4}$ after day 80 are probably due to clogging of air diffusers, which frequently occurs (personal contacts). However, clogging of the air diffusers was not taken into consideration because there was not enough information to model it.

Despite the instances of mismatch between model predictions and measurements shown in Fig. 1, Fig. 2 and Fig. 3 , the developed model is generally able to predict the daily dynamics and trends in $C O D_{\text {tot }}, \mathrm{NH}_{4}$ and $\mathrm{NO}_{3}$ concentrations of the activated sludge effluent. That is, the developed model is capable of predicting reasonably the long-term performance of Riqqa activated sludge system.

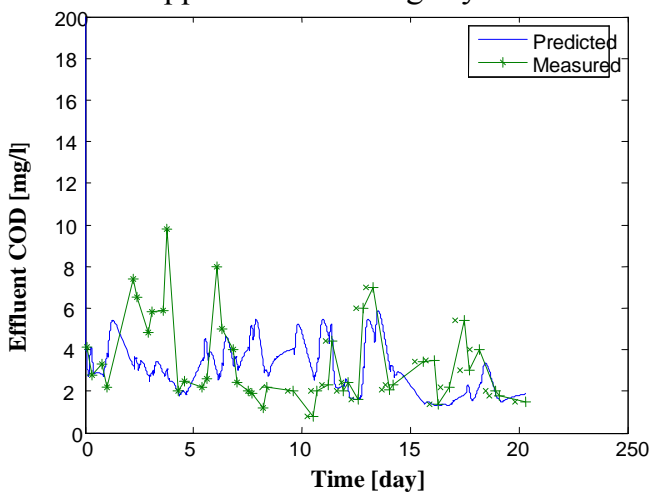

Fig. 1. Calibration results of $C O D_{\text {tot }}$ of the secondary effluent.

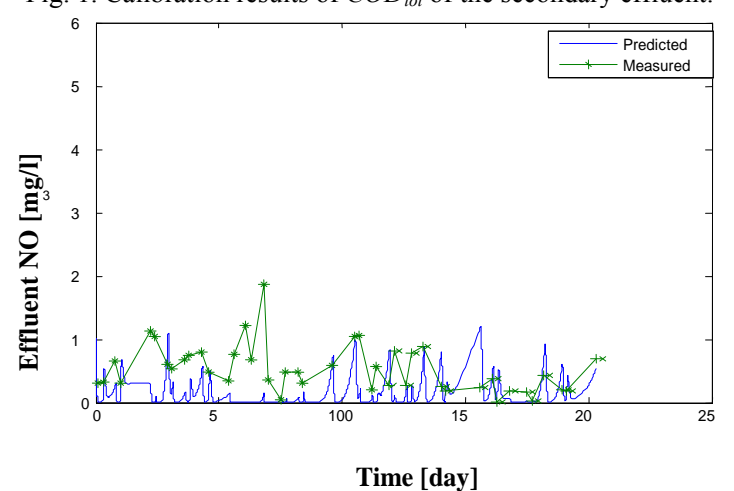

Fig. 2. Calibration results of $\mathrm{NO}_{3}$ of the secondary effluent.

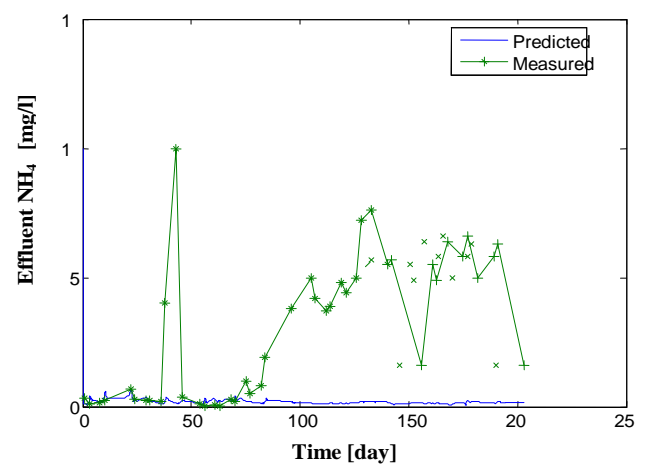

Fig. 3. Calibration results of $\mathrm{NH}_{4}$ of the secondary effluent. 
Results of model validation are presented in Fig. 4- Fig. 6. These figures show that during the validation period model predictions were not as good as that during the calibration period (Fig. 1-Fig. 3). During the first 80 days especially, there were significant mismatch (Fig. 5 and Fig. 6) and high dynamics (Fig. 4) compared to the measurements taken during the same period. Given the fact that validation data were mainly for the winter season, poor model predictions during the validation period can be attributed to sludge bulking and foaming problems the Riqqa plant used to encounter every winter. Abusam [4] proposed to conduct a study to find out the root causes of sludge bulking and foaming problems encountered frequently at Kuwait's wastewater treatment plants.

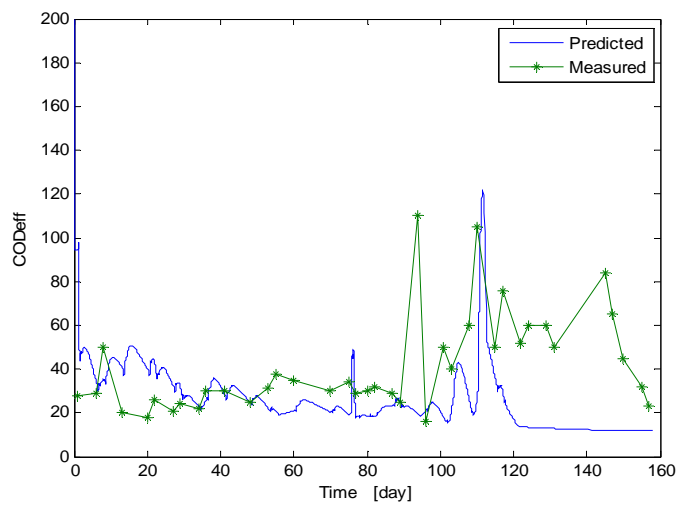

Fig. 4. Validation results of $\mathrm{COD}_{\text {tot }}$ of the secondary effluent.

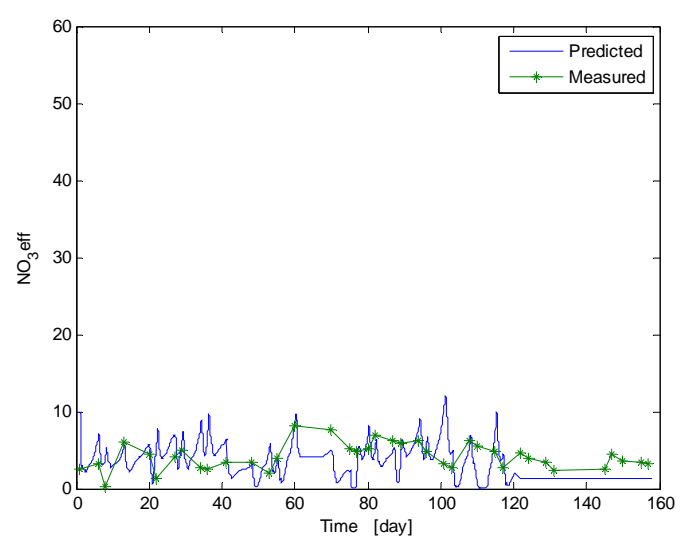

Fig. 5. Validation results of $\mathrm{NO}_{3}$ of the secondary effluent.

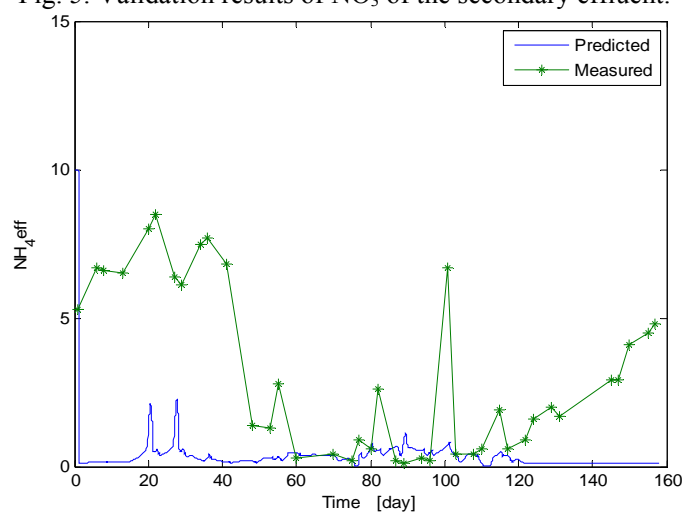

Fig. 6. Validation results of $\mathrm{NH}_{4}$ of the secondary effluent.

From Fig. 5 and Fig. 6, it is apparent that the impact of the winter season on nitrogen removal is more pronounced than that on COD removal (Fig. 6). This was expected since autotrophic bacteria are more sensitive to drop in water temperature than heterotrophic bacteria. However, the inadequate supply of oxygen due to frequent clogging of air diffusers might have also contributed to poor nitrogen removal during the winter season.

For improving the model prediction, more accurate information is needed about the aeration patterns and aerators clogging incidences. However, the accuracy of model predictions depends basically on the modeling purpose. In spite of the few cases of discord between model result and measured values, the developed model appeared to be very much effective for the purposes of this study, which was assessing the system's present and future performance through various scenarios of operation. Furthermore, the developed model can be used to propose more efficient control strategies for the system.

\section{CONCLUSIONS}

ASM1 model for Riqqa activated sludge system was developed on SIMBA software, using long-term, routinely measured wastewater quality parameters. This was the first time to use ASM1 to model a full-scale wastewater treatment plant in Kuwait. $C O D_{\text {tot }}$ was fractionated according to the methods reported in literature and with the help of respirometry measurements. However, TN was fractionated as suggested by SIMBA (default fractions).

Steady-state calibration had shown that $\mathrm{X}_{\mathrm{I}}$ was about $45 \%$ of $\mathrm{COD}_{\text {tot }}$, while $b_{H}$ was $0.10 \mathrm{~d}^{-1}$ and $b_{A}$ was $0.05 \mathrm{~d}^{-1}$. Dynamic calibrations had resulted in reasonable predictions of $C O D_{t o t}, \mathrm{NH}_{4}$ and $\mathrm{NO}_{3}$ concentrations of the secondary effluent at $\mathrm{Y}_{\mathrm{H}}, K_{\mathrm{OH}}, b_{H}, b_{A}, K_{S}$ and $\eta_{g}$, equal to $0.67,0.5,0.10$, 0.5 , and 30 , respectively. The value of the only parameter calibrated for the clarifier model $\left(r_{p}\right)$ was found to be equal to $6.86 \mathrm{e}-3 \mathrm{~m}^{3} / \mathrm{g}$.

In spite of the few cases of discord between model result and measured values, the developed model appeared to be very much effective for the purposes of the study. The results of model validation indicated that the developed model reasonably describes the long-term carbon and nitrogen processes taking place in Riqqa activated sludge system.

The developed model can be used to predict the system effluent quality and to propose more efficient control strategies. Further, the ASM1 parameter values obtained will be useful in modeling other activated sludge systems in the country.

\section{ACKNOWLEDGMENTS}

The author acknowledges with gratitude the funding support of the Kuwait Institute for Scientific Research (KISR) and the Kuwait Foundation for the Advancement of Sciences (KFAS) for the study.

\section{REFERENCES}

[1] K. V. Gernaey, M. C. M. V. Loosdrecht, M. Henze, M. Lind, and S. B. Jorgensen, "Activated sludge wastewater treatment plant modeling and simulation: state of the art," Environmental Modeling \& Software, vol. 19, no. 9, pp. 763-783, September 2004.

[2] M. Henze, W. G. Gujer, G. V. R. Marrias, and T. Matsuo, "Activated sludge model," International Water Association, London. No. 1, 1987.

[3] C. Fall, J. L. M. Navia, and E. Soto, "Full activated sludge model no. 1 calibration experience at medium-size wwtp in Mexico," Water Science and Technology, vol. 60, no. 12, pp. 3069-3082, 2009. 
[4] A. Abusam, "Filamentous bacteria and associated problems in Kuwait's activated sludge systems," Kuwait Institute for Scientific Research, KISR 11529, Kuwait, 2010.

[5] M. F. Hamoda, I. A. Ghusain, and N. Z. A. Mutairi, "Sand filtration of wastewater for tertiary treatment and reuse," Desalination, vol. 164, no. 1-3, pp. 203-211, 2004

[6] Manual Nitrogen Control, EPA/625/R-93/010, Environmental Protection Agency, Washington D.C., USA, 1993.

[7] Davis, Turbulence Phenomena: An Introduction to the Eddy Transfer of Momentum, Mass, and Heat, Particularly at Interfaces, Academic Press, New York, 1972.

[8] I. Takacs, G. G. Patry, and D. Nolasco, "A dynamic model of the clarification-thickening process," Water Research vol. 25, no. 10, pp. 1263-1271, October 1991.

[9] Standard Methods for Examination of Water and Wastewater, 20th ed., American Public Health Association, Washington D.C., USA, 1998.

[10] M. Henze, W. Gujer, T. Mino, T. Matsuo, M. C. M. Wentzel, and G. V. R. Marias, "Activated sludge model no. 2," IAWQ Scientific and Technical Report, no. 3, London, UK, 1995.

[11] A. Abusam, K. J. Keesman, G. van. Straten, H. Spanjers, and K. Meinema, "Sensitivity analysis in oxidation ditch modeling - the effect of variations in stoichiometric, kinetic and operating parameters on the performance indices," Journal of Chemical Technology and Biotechnology, vol. 76, no. 4, pp. 430-438, March 2001
[12] A. Abusam and K. J. Keesman. (2002). A sensitivity analysis of the secondary settling tank double-exponential model. European Water Management [Online]. (7). pp. 1-9. Available: http://www.ewaonline.de/journal/2002_07.pdf

[13] D. Orhon and N. Artan, Modeling Activated Sludge Systems, Technomic Publishing Co., USA, 1994.

[14] M. L. Davis and D. A. Cornwell, Introduction to Environmental Engineering, 3rd ed., McGraw-Hill, Singapore, 1998.

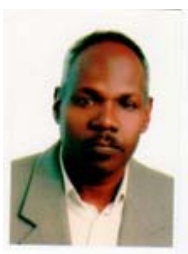

Abdallah Abusam was born in 1956, Sudan. He received his B.Sc. (hons) in civil engineering from the University of Khartoum, Sudan, in 1982 and a M.Sc. in sanitary engineering from the University of Khartoum, Sudan, in 1986 and a MPH in environmental \& occupational health sciences from the University of Illinois at Chicago, USA, in 1990; and $\mathrm{a} \mathrm{PhD}$ in environmental engineering from Wageningen University, The Netherlands 2001.

$\mathrm{He}$ is a researcher and manager of the Wastewater Program at the Kuwait Institute for Scientific Research, Kuwait. He has published more 60 articles in conference proceedings and refereed journals.

Dr. Abusam is a fellow member of Sudan Engineering Society. He is also a member of the Dutch Association for System and Control. 